which gave 0.246 to 0.249 , an average of $0.248 \mathrm{cc}$. carbon dioxide at $760 \mathrm{~mm}$. and $0^{\circ} \mathrm{C}$. The correction therefore is a constant quantity equal to $0.248 \mathrm{cc}$. Every chemist who uses this method, has of course to ascertain this factor for himself.

In this method o. Io cc. carbon dioxide equals 0.01 per cent. carbon in the iron. It is easily seen that the small variation of the carbon dioxide in the reagents cannot have any influence on the accuracy of the determination.

The authors give the results of their carbon determinations in some normal irons, which they received through Professor $\AA$ kerman from the collection of the Academy of Mines of Stockholm and which come from Miller, Metcalf and Parkin, Pittsburg, $\mathrm{Pa}$. The four samples cuntained the following quantities of carbon in 100 parts :

\begin{tabular}{|c|c|c|c|c|}
\hline I $\ldots \ldots \ldots \ldots \ldots$ & $\begin{array}{c}\mathrm{I} \\
1.421\end{array}$ & $\begin{array}{c}2 . \\
0.817\end{array}$ & $\begin{array}{c}3 . \\
0.447\end{array}$ & $\begin{array}{c}4 . \\
0.163\end{array}$ \\
\hline $2 \ldots \ldots \ldots \ldots$ & I.4I9 & 0.810 & $0.45^{I}$ & 0.169 \\
\hline $3, \cdots \cdots \cdots \cdots$ & I. $45^{8}$ & 0.817 & 0.455 & 0.175 \\
\hline $4 \ldots \ldots \ldots \ldots$ & $1.43^{2}$ & 0.813 & $0.45^{1}$ & 0.164 \\
\hline $5 \ldots \ldots \ldots \ldots$ & 1.417 & $\cdots$ & 0.442 & 0.169 \\
\hline $6 \ldots \ldots \ldots \ldots$ & I. $43 \mathrm{I}$ & $\cdots$ & 0.444 & $\cdots$ \\
\hline Average.. & .430 & $0.8 I_{4}$ & 0.448 & 0.168 \\
\hline
\end{tabular}

Whenever iron which contains graphite is analyzed by this method, there is left a residue of fine shining scales of graphite, swimming on the fusion; these can be filtered off after solution of the fusion in hydrochloric acid and taken up by a platinum filter with asbestos (figures 4 and 5 ). The authors weighed the filter first with the graphite, and then after the burning of the graphite in a current of air loaded with nitrous gases (figure 5) and obtained the weight of the graphitic tesidue as mentioned in Ber. d.chem. Ges., 23, 1401, 1890.

\title{
RECENT METHODS IN FERTILIZER ANALYSIS.
}

FidTed By EDwin J. Haley, A. M.

TOCK'S rapid method for the determination of nitrogen in $S$ organic compounds (Analyst, 17, No. 194, 109) has aroused more than passing notice and discussion. Briefly, the original method is as follows: From $0.5^{-1}$ gram of substance is mixed in 
a small beaker with ten cc. sulphuric acid (sp. gr. 1.s4), and five grams of native manganese dioxide (passed through a thirty-six mesh sieve). The flask is heated on an iron plate until the contents assume a dark green color, due to the formation of manganic sulphate. This indicates the end reaction. The flask is cooled. water added, and an excess of sodium hydroxide in solution (twenty grams sodium hydroxide for ten cc. sulphuric acid) is added, and the distillation and titration conducter in the usual way.

The new method can not be considered simply a modification of Kjeldahl's process, for the principal oxidant in the latter process is sulphuric acid while manganese dioxide is the oxidizing reagent in Stock's process. The author of the method claims to have oxidized a sample of bone meal in three minutes and determined the nitrogen in fifty minutes from the time of weighing out.

Manures and other substances containing a large amount of chlorides can not be treated directly by this method. The chlorides must first be decomposed by heating with sulphuric acid alone for twenty minutes and the manganese oxide can then he added at once and the process continued as usual.

The following are experimental results obtained by Stock:

\begin{tabular}{|c|c|c|}
\hline & $\begin{array}{l}\text { Nitrogen by } \\
\text { new method }\end{array}$ & $\begin{array}{l}\text { Nitrogen by } \\
\text { combuntion. }\end{array}$ \\
\hline$\ldots \ldots \ldots \ldots$ & $3.6+$ per cent. & $3.5+$ per cent. \\
\hline${ }^{\star} \ldots \ldots$ & 3.49 & 3.69 \\
\hline Fish flesh..... & 7.51 & $7 \cdot+1$ \\
\hline
\end{tabular}

The apparatus used by Stock in his first experimentation consisted of a copper boiler, $600 \mathrm{cc}$. capacity, closed by a screw cap and India rubber washer. This cap carries, a topped funnel for the introduction of sodium hydroxide solution, and a wide evolution tube to serve as a reflux tube in case of frothing. The erolution tube is closed by a rubber stopper carrying a tube bent at such an angle as will permit its passingr down the center of a Wurtz flask, which serves as a washing flask for the vapors from the copper boiler. Both boiler and flask are provided with burners and both must be kept boiling throughout the experiment. The Wurtz flask is in turn connected with a fourteen-inch Liebig condenser. set vertically, and this termi- 
nates in a $500 \mathrm{cc}$. receiving flask fitted with a guard tube filled with beads through which the standard acid is run into the receiver. The open ends of the tubes are all ground off at an acute angle so as to prevent the formation of piston-drops.

Later (Analyst, 18, No. 203, 58) Stock simplified his apparatus by dispensing with one of the two Bunsen burners and made it consist of a Wurtz flask, I 50 cc. capacity, the tube from which runs into the condenser. The flask is kept at boiling point by the ammoniacal steam from the distilling flask. By this simplification the conveyance of sodium hydrate into the distillate is prevented.

The chief objection raised to the above method was the loss of nitrogen due to progressive oxidation finally producing nitric acid.

Skertchly (Analyst, Nov., I892) gave as the results of his experimentation with the method that it failed on account of the loss of nitrogen dne to the mixture of sulphuric acid and manganese dioxide acting upon nitrogenous substances like sulphuric acid and potassium permanganate causing loss of ammonia.

Stock explained Skertchly's loss of ammonia to be due to a want of division of the samples whence nitrogen was left unconverted, and also to a non-conformity to the process itself, for Skertchly used as an oxidant manganese dioxide containing 40.56 per cent. manganese dioxide while Stock used eighty to ninety-seven per cent. manganese dioxide. Hehner holds it is immaterial whether manganese dioxide is inferior or not, provided it contains sufficient dioxide to oxidize the substance; and as the point of complete oxidation is denoted by the green color there should be no reason for loss of nitrogen due to incomplete oxidation.

Böttcher (Lands. I'r. Stat., 41, 170-4) recommends the Jodlbauer modification for the determination of nitrogen in nitrates and Wilfarth's modification (addition of metallic oxides during digestion) for materials difficult to decompose, such as ground bone, ground fish, etc. He found that the addition of mercury gives a higher result in some analyses than copper and prefers to add I.5 grams of zinc dust instead of potassium sulphide and zinc dust in the distillation with sodium hydroxide. 
The zinc dust alone suffices to free the ammonia from the mercuro-ammonium compounds.

Winton, of the Connecticut experiment station, in a bulletin of June, I892, proposes the following modified Gunning-Kjeldahl method in presence of nitrates: 0.3 to I gram of material is digested with thirty cc. Scovell's salicylic acid nixture for two hours. Two grams of zinc dust are added and a slow heat applied. Ten grams of potassium sulphate are added and the boiling continued until the solution is colorless or straw-colored, due to the presence of iron. As the mixture begins to solidify on cooling, water is added, and the distillation with sodium hydroxide carried on in the usual manner. The results were very satisfactory as compared with the Scovell-Jodlbauer method. The greatest discrepancy was $O$. I per cent. and the arerage difference between the two methods was 0.05 per cent.

Some important experiments have been made and interesting results been secured on the reliability of the determination of phosphoric acid as magnesium pyrophosphate by the molybdic acid method. Neubauer (Ztschr. anorg. ( $/ 2 \mathrm{~cm}, 8802,2,45$ ) after exhaustive experimentation concluded that a part of the phosphoric acid was volatilized by the strong ignition necessary to convert the magnesium ammonium phosphate into the magnesium pyrophosphate. When large quantities of ammonium salts are present, $\mathrm{Mg}\left(\mathrm{NH}_{4}\right)_{4}\left(\mathrm{PO}_{4}\right)_{2}$ is precipitated as well as the normal $\mathrm{MgNH}_{4} \mathrm{PO}_{4}$. The former salt upon ignition reacts according to the following formula:

$$
\mathrm{Mg}\left(\mathrm{NH}_{4}\right)_{4}\left(\mathrm{PO}_{4}\right)_{2}=\mathrm{Mg}\left(\mathrm{PO}_{3}\right)_{2}+4 \mathrm{NH}_{3}+2 \mathrm{H}_{2} \mathrm{O}
$$

And upon continued ignition the metaphosphate is converted into the pyrophosphate with loss of phosphoric anhydride:

$$
2 \mathrm{Mg}\left(\mathrm{PO}_{3}\right)_{2}=\mathrm{Mg}_{2} \mathrm{P}_{2} \mathrm{O}_{7}+\mathrm{P}_{2} \mathrm{O}_{8} \text {. }
$$

The amount of anhydride lost is proportional to the amount of $\mathrm{Mg}\left(\mathrm{NH}_{4}\right)_{4}\left(\mathrm{PO}_{4}\right)_{2}$ formed, which in turn is dependent upon the quantity of ammonium salts in solution.

Breyer and Schweitzer (Chem. Ztg., r89ं, 1720-23) question the accuracy of the Lindo-Gladding method for potassium. They claim that an examination of the potassium-platinic chloride precipitate showed the presence of sulphuric acid, lime, magnesia, and ammonia. As their results were low in comparison 
with the Fresenius method in spite of these impurities they concluded there was a loss of potash in the determination, and tests of the alcoholic washings showed potash. A sample of sylvinite contained 15.45 per cent. potash by the Fresenius method and I4.85 per cent. potash by the Lindo-Gladding method. The platinum precipitate of the former was free from sulphuric acid, lime, magnesia, or ammonia. The ammonium chloride and alcoholic washings in the Lindo-Gladding method contained potash equivalent to 1.46 per cent. potash for 0.5 gram of substance. Analysis of the platinum precipitate showed ammonia equivalent to $0.0176 \mathrm{gram}$ of ammonium-platinic chloride or in weight to 0.0034 grams potassium-platinic chloride or 0.68 per cent. potash for 0.5 gram of substance. Sulphuric acid and magnesia were also recognized qualitatively in the potassiumplatinic chloride.

Holleman (Chem. Ztg., I892, I920-2 I) explains the unsatisfactory results obtained by Breyer and Schweitzer in that, notwithstanding the large quantity of alcohol used for washing the precipitate, the soluble platinum salts were not all removed and consequently in the washing with ammonium chloride, ammonium-platinic chloride was formed which remained on the filter as an impurity. To this Holleman attributed the presence of ammonia in the platinum precipitate and not to a partial replacement of the potash of the platinum salt by ammonia in washing.

\title{
ALUMINUM.
}

BY R. I. PACKARD.

\begin{abstract}
$A$ SIDE from the merely industrial aspect of the subject, the $A$ history of aluminum is unique in affording an opportunity to study the growth, absolutely $a b$ initio and within the space of one generation of men, of a metallurgical industry operating upon a new metal. Thirty-five years ago aluminum was as much a chemical curiosity as any one of the rare metals is to-day. Through the efforts of Deville it first acquired a commercial character, and its extraction was transferred from the sphere of laboratory experiments to become a metallurgical process. Since
\end{abstract}

I From Bulletin of the U. S. Geological Survey, Aptil, 1893. 